\title{
Rectal prolapse in pregnancy: a case report
}

\author{
RS Jamabo ${ }^{1}$ and RN Ogu ${ }^{2}$
}

\begin{abstract}
Rectal prolapse occurs when a mucosal or full thickness layer of rectal tissue slides through the anal orifice. It is relatively infrequent and occurs commonly in elderly women. This report is to bring to focus the possibility of a rectal prolapse being misdiagnosed as haemorrhoids in pregnancy. A case of a 35-year-old woman, gravida 4 , para 3+0, found to have a large rectal prolapse but misdiagnosed as prolapsed haemorrhoids at 34 weeks gestation is reported. Although rectal prolapse is not a common condition during childbearing years, it is instructive for obstetricians and midwives to be vigilant in all cases of pregnant women presenting with rectal protrusion or bleeding.
\end{abstract}

\section{INTRODUCTION}

Rectal prolapse is classified into complete or full thickness prolapse and incomplete or mucosal prolapse. Complete prolapse occurs in older adults while the latter occurs both in children and adults. This report is based on complete rectal prolapse, which is commoner in females and it is associated with weak pelvic and anal musculature. Rectal prolapse is an anatomical abnormality and requires surgical correction.

KEY WORDS: Prolapse, rectum, gestation, haemorrhoid

Departments of ${ }^{1}$ Surgery, and ${ }^{2}$ Obstetrics and Gynaecology, University of Port Harcourt Teaching Hospital, Port Harcourt, Nigeria

Correspondence: Dr R. N. Ogu, 89 Victoria Street, P.M.B. 6185, Port Harcourt, Nigeria. E-mail: drjamabo@anglican-nig.org

\section{CASE REPORT}

A 35-year-old woman, gravida 4 , para $3+0$, with 34 weeks gestation was referred to the surgical clinic for what was diagnosed as third degree haemorrhoids. She gave a three-month history of troublesome rectal bleeding and prolapsing anal mass at defecation. The mass was always reduced manually. Rectal examination revealed a patulous anal opening, and on bearing down, approximately $5 \mathrm{~cm}$ of rectum prolapsed. It was immediately reduced and held in place with moist gauze pack. As a temporary measure, a Thiersh wiring was done with the aid of a local anaesthetic by infiltrating $1 \%$ lignocaine into the anal sphincter. She could not tolerate it and had to be taken down after two weeks.

At 39 weeks gestation, she had spontaneous vaginal delivery of a normal baby with an embarrassing large prolapse of the rectum ( $8 \mathrm{~cm}$ long). The prolapse was reduced as usual. Definitive repair of the prolapse was

(C) CMS UNIBEN JMBR 2005; 4(1): 92-93 
by the Altemeier's method of perineal rectosigmoidectomy carried out three months postpartum.

\section{DISCUSSION}

Rectal prolapse is rare during childbearing years, as only one case occurring during pregnancy has so far been reported. ${ }^{1}$ The aetiology of rectal prolapse is not clear. Pelvic floor dysfunction secondary to chronic straining at defecation and anal sphincter abnormality are considered as been contributory. ${ }^{2}$ Childbearing appears to play a limited role in its pathogenesis since nulliparous women are also at risk of developing rectal prolapse. ${ }^{3}$ History of perineal lacerations may be a risk factor. ${ }^{1}$ There may be hereditary factors in some families. ${ }^{4}$ Rectal prolapse is far more common in women than men; the male/female ratio is $1: 6 .{ }^{5}$ Its incidence rises sharply after the age of 50 and peaks in the seventh decade. ${ }^{5}$ Rectal prolapse is diagnosed by taking a careful history and asking the patient to strain as if having a bowel movement. A prolapse of $5 \mathrm{~cm}$ or more is diagnostic of full thickness rectal prolapse. ${ }^{6}$ A prolapsed haemorrhoid is usually about $2 \mathrm{~cm}$ long. At times the prolapse may be hidden or internal. In such cases a videodefecogram and/or anorectal manometry may be helpful. ${ }^{7}$

Management of rectal prolapse in pregnancy has to be modified. Immediate definitive repair is not feasible. In the case reported, a temporary Thiersch procedure was done but had to be taken down within two weeks because the patient could not tolerate it. In order to avoid the possibility of worsening the prolapse, consideration should be given to passive forceps delivery under epidural anaesthesia. ${ }^{1}$ Our case declined to have any form of assisted delivery, hence the embarrassing situation of having a large prolapsed rectum during the second stage of her labour.

\section{CONCLUSION}

Although rectal prolapse is an uncommon condition in childbearing women, it could masquerade as haemorrhoids, which is common in pregnancy, in view of the similarity in their mode of presentation, namely, bleeding per rectum and/or a mass protruding from the anal verge. In such cases, they must be made to strain to clinch the diagnosis.

\section{Reference}

1. Viera AJ and Larkin-Pettigrew M. Rectal prolapse during pregnancy. A case report. $J$ Reprod Med 2000; 45(1): 45-47.

2. Sze EH, Sherard GB 3rd and Dolezal JM. Pregnancy, labor, delivery and pelvic organ prolapse. Obstet Gynecol 2002; 100(5 Pt 1): 981-986.

3. Karasick S and Spettell CM. Defecography: does parity play a role in the development of rectal prolapse? Eur Radiol 1999; 9(3): 450-453.

4. Eu KW and Seow-Choen F. Functional problems in adult rectal prolapse and controversies in surgical treatment. Br J Surg 1997; 84: 904-911.

5. Liberman H, Hughes $\mathrm{C}$ and Dippolito A. Evaluation and outcome of the Delorme procedure in the treatment of rectal outlet obstruction. Dis Colon Rectum 2000; 43(2): 188-192.

6. Tobin SA and Scott IH. Delorme's operation for rectal prolapse. Br J Surg 1994; 81: 16811684.

7. Peters WA 3rd, Smith MR and Drescher CW. Rectal prolapse in women with other defects of pelvic floor support. Am J Obstet Gynecol 2001; 184(7); 1488-1494. 